\title{
Macau: uma literatura plural? ${ }^{1}$
}

\section{Mônica SIMAS $S^{2}$}

\section{Ponto de partida}

Na última década, o interesse sobre lugares de acentuada interseção étnica e cultural parece ter aumentado consideravelmente e aqueles nas fronteiras da presença portuguesa não serão exceção. Considerando que, de meados do século XX, depois da II Grande Guerra em diante, o mundo tem enfrentado várias guerras de fundo étnico como as da Bósnia, do Camboja, do Irã e do Iraque, a Região Administrativa Especial de Macau (RAEM), por ter conseguido defender, até o momento, um convívio seguro aos seus habitantes de tão variadas origens, constitui, sem dú-

\footnotetext{
1 Uma versão em inglês deste texto foi publicada em Asian Diasporic Visual Cultures and Americas, v. 2. Special Issue: Memory and Migration, 2016. ISSN: 2352-3077; E-ISSN: 2352-3085.

2 Professora Associada na Faculdade de Filosofia, Letras e Ciências Humanas da Universidade de São Paulo (USP) e coordenadora do LIA (Laboratório de Interlocuções com a Ásia), onde tem pesquisado as interfaces culturais entre Brasil, Portugal e China. Apoio CNPq; Fapesp-Bolsa Pesquisa no Exterior; monicasimas@usp.br
} 
vida, um lugar especial de reflexão. Se se compararem, ainda, as desastrosas campanhas portuguesas na África e as sofridas guerras pela independência que aqueles países tiveram que enfrentar contra Portugal - Guiné-Bissau, Angola, Moçambique, São Tomé e Príncipe, e Cabo Verde -, o contraste com o processo diplomático de transferência da administração portuguesa de Macau para a República Popular da China (1999) torna a sua história uma exceção absoluta. Também na Ásia, a desocupação de Goa, na década de 1960, e a ocupação de Timor pela Indonésia, logo após a Revolução dos Cravos (1974) em Portugal, mostram que os choques entre grupos e nações estão sempre em curso e que os imperativos de convivência pacífica são uma frágil construção que precisam ser bem preservados.

É Wordie (2013) que, entre seus livros sobre lugares, chama a atenção para o fato de Macau ser descrita comumente e de uma forma simplista como uma sociedade dual, de matriz portuguesa e chinesa, mas que a indicação é imprópria, usada em certos discursos oficiais, fomentando uma mitologia da cidade que não corresponde à sua realidade tão interessante quanto os múltiplos legados que ela contém. Ao seu ver, a realidade histórica é bem mais diversa e particular do que o slogan mais geral de lugar de encontro entre "o Oriente e o Ocidente", sendo formada por várias minorias étnicas que residem na região ou que formaram o sincrético grupo denominado de macaense, hoje, vivendo, por sua vez, diasporicamente espalhado pela América do Norte e do Sul, Canadá e Portugal. O ponto principal do texto de Wordie (2013) é que Macau, como lugar de passagem, foi também o de recepção e residência e, portanto, de contínuas trocas culturais, afetivas e econômicas. Só para dar alguns exemplos, ele mostra como chineses de Burma e da Indonésia vão se estabelecer nos arredores de Mong Há; como os persas fizeram história no ter- 
ritório, sendo os muçulmanos que hoje habitam em Macau bastante discretos comparados aos que residem em outras geografias próximas. Mostra como no Bairro da Horta e Mitra, para os portugueses, ou "Jardim do Pequeno Passarinho", para os chineses, os tailandeses vão desenvolver pequenos negócios desde que o antigo Hotel Estoril, hoje abandonado, começou a buscar massagistas para incrementar o turismo local. Indo além da descrição de grupos nos espaços específicos, Rocha (1998) constata: "Se aceitarmos que Macau é uma sociedade multicultural, então tudo deve fluir dessa característica: as suas leis, as suas instituições, as suas escolas e os seus currículos. A não ser assim, temos uma sociedade multicultural e cidadãos monoculturais" (p. 26). Para o autor não basta justapor monoculturas para se desenvolver uma educação voltada para a multiculturalidade porque esse tipo de organização transporta consigo o gérmen da segregação. Para ele, são necessárias "abertura, troca, interação comunicacional, reciprocidade, solidariedade objetiva" (Rocha, 1998, p. 34). A questão que se quer sublinhar, no espaço dessa breve reflexão, é a de pensar quais implicações as colocações apresentadas trazem à Literatura? É possível se pensar em uma Literatura de Macau multilíngue e multicultural? As análises de repertórios literários da região parecem indicar uma necessária reflexão sobre a própria definição de literatura, pois, até o momento, ela tem sido estudo no âmbito das monoculturas linguísticas localizadas no espaço excêntrico dos cânones produzidos fora do seu próprio território físico. Pensar a Literatura de Macau significa pôr à prova a validade de valores nacionais ou regionalistas e também as alterações por que a própria historiografia literária tem passado desde a década de 1970. 


\section{Molduras teóricas}

Olinto (1996) reforça que, desde que a chamada "Nova História”, na França, postulou rupturas com os modelos tradicionais historiográficos, as historiografias literárias foram deixando de veicular valores essencialistas e passaram, cada vez mais, a integrar a discussão sobre a Literatura com outras das Ciências Sociais. Dos construtivistas mais radicais, como Schmidt ou Rusk, até os cognitivistas, como Maturana, passou a haver uma tendência de teóricos discutirem seus próprios limites, evitando noções de verdade ou aquelas antigas de literariedade. $\mathrm{O}$ sistema literário, nesse contexto, passou a designar condições de produção e de recepção complexas e a ideia de que o texto literário em si e por si pode constituir o objeto de estudo foi desaparecendo.

No campo dos estudos das Literaturas Africanas de Língua Portuguesa, Moraes (2014) identifica que as relações entre literatura e sociologia são antigas, principalmente com a repercussão que os trabalhos de Antonio Candido tiveram no âmbito acadêmico. Ela repara que, no Brasil, tem sido frequente a crítica seguir o modelo teórico proposto por Antonio Candido, com destaque para a sua noção de sistema literário, mas com adaptações, e que vários autores, como o estudado por ela, Ruy Duarte de Carvalho, resistem às noções tal como definidas nessas molduras mais antigas. O que se pode observar é que cada uma dessas literaturas implica questionamentos próprios e tem que ser tratada em suas especificidades.

\section{Crítica e sentido comunitário}

Na apresentação da Antologia de Poetas de Macau (1999), bilíngue em línguas chinesa e portuguesa, Laborinho começa a 
descrever algumas dificuldades de se definir a Literatura de Macau e percorre um artigo de Cheng Wai-Ming em que a Literatura chinesa de Macau entre os anos 1980 e o princípio da década de 1990 é analisada, para mostrar o quão difícil é estabelecer contornos dessa literatura. Laborinho (1999) sublinha que o autor citado considera que a Literatura de Macau é formada por todas as línguas que tematizem o território mesmo que seu autor não tenha ali nascido e crescido, e por quaisquer obras de naturais de Macau. Em contraste, num artigo de outro crítico, Weng Chong, citado no seu mesmo texto, aparece um outro critério, que seria o "estilo literário nacional", tema, assunto e cor local, mas revelando uma grande dificuldade em definir o conceito de "macaense". Parece o restringir ao significado de "filho da terra" (entendido como euroasiático) para, depois, abranger ações dele decorrentes, como culinária e linguagem própria. Portanto, o autor restringe a literatura à temática macaense, apenas incluindo a literatura de expressão portuguesa, sem dúvida, uma forma muito "estrita" de se entender o conjunto dessa literatura.

Retorno ao texto de Cheng (1995), "Literatura chinesa de Macau entre os anos oitenta e os princípios da década de noventa", citado no prefácio de Ana Paula Laborinho, para sublinhar outros aspectos bastante importantes. Logo no início do seu artigo, do mesmo modo que entende que obras editadas fora da região possam ser inseridas na literatura de Macau, como as de Yi Ling ou Wang He, publicadas em Hong Kong e Taiwan, observa que não se deveria concluir que todas as obras que sejam publicadas e editadas na região sejam consideradas "literatura macaense". A observação é importante por dois aspectos: 1) porque, de alguma forma, busca atrelar a noção de literatura a uma noção de construção de sentido comunitário e 2) porque parece alargar a noção de "macaense". A formulação é muito interessante, por- 
que é uma das primeiras análises a fazer uma distinção entre as obras escritas por chineses que nasceram e viveram no território daqueles que ingressaram, da República Popular da China, como estrangeiros. O que parece estar em jogo, nessa formulação, é a importância de se fazer uma ligação entre a produção textual e um projeto cultural que traga significação histórica e, portanto, na abrangência do termo, um sentido "político" a Macau.

Em "A escrita de Macau: uma literatura de circunstâncias ou as circunstâncias de uma literatura", Brookshaw (2010) recorda, antecipando as reflexões apresentadas por Moraes (2014), que essa dificuldade já estava presente nas literaturas africanas das últimas décadas ou na literatura brasileira em determinadas épocas dos séculos XIX e XX. No contexto específico de Macau, e o mesmo servirá para Goa, o professor enfatiza que a noção de literatura deveria abranger, além das categorias tradicionais de ficção, poesia e teatro, a tradição jornalística moderna que remonta ao século XIX. Também defende que, devido ao fato de Macau ser um lugar de "chegadas" e "partidas", muitas vezes, sendo o seu passado evocado através de memórias, os livros publicados fora da região, por autores que emigraram, sejam inseridos no contexto do que se define como literatura de Macau. Ambos, Brookshaw e Laborinho, consideram que o termo writing Macau, paralelo ao writing Hong Kong, proposto por Akbar Abbas (2002), em Culture and the Politics of Disappearance [ou: Hong Kong: Cultural and the Politics of Disappearance], indicando uma formação de corpus literário que não esteja ligada necessariamente à questão de autores e temas, mas sim à maneira pela qual o espaço se inscreve em textos, como espaço cultural, tende a ultrapassar a forma mais tradicional de se pensar o cânone.

Como disse Laborinho, na "Introdução" de Macau na Escrita, escritas de Macau, "ao adotarmos o conceito 'Escrever 
Macau/Writing Macau', é possível delimitar um corpus literário que problematize Macau como um espaço cultural permeado de fricções" (2010, p. 16). O termo teria sido, primeiro, usado para a literatura de Hong Kong, depois, transposto para a literatura de Goa, na dissertação de mestrado de Evandro Luis Von Sydow, $F(r) i c c ̧ \tilde{e} e s$ Goesas: vários mundos numa só vida, defendida na Universidade Federal Fluminense, em 2008, e hoje tem sido utilizado, de forma produtiva, para se pensar também a literatura de Macau. Mas será o espaço, mesmo tomado em sua acepção mais alargada da cultura, necessariamente nuclear ao pensarmos sobre corpus literário?

Parece que a questão "associativa", levantada por Cheng (1995) para se buscar definir essa literatura, não seja menos importante do que a outra. Talvez, ambas somadas, possam alargar horizontes, principalmente com relação ao cânone, mesmo que não consigam traçar contornos do fenômeno literário de Macau de forma exata (ou definitiva).

Por isso, seria, talvez, interessante que se revisse outro texto de Candido (1967/1985), "A literatura na evolução de uma comunidade", que retrata o contexto paulista do Brasil e que toca exatamente nessa questão. O professor já descartava o critério de nascimento, para falar da literatura paulista, em detrimento a um outro, que considerava mais "compreensivo" e que se definia a partir "da participação na vida social e espiritual da cidade de São Paulo" (p. 139). Nessa formulação, literatura já era entendida como "fato eminentemente associativo" (CANDIDO, 1967/1985, p. 139), que não existe sem "um sistema de valores que enforme a sua produção e dê sentido à sua atividade" (p. 140). Parece que essa definição é bem abrangente ao mesmo tempo que evita um relativismo absoluto, desde que o "espaço social", no contexto atual, seja redimensionado e compreendido fora da fixidez do 
local, ou seja, relacionado também aos espaços das migrações ou, ainda, de um modo mais geral, ao mundo das viagens. Dessa forma, a literatura diaspórica, por exemplo, poderia contribuir à diversidade cultural do espaço social do "local de destino" ao mesmo tempo participar da "vida espiritual" dos valores do "local de origem", ou seja, nem sempre o local da vida social é o mesmo daquele dos valores mentais e culturais de uma determinada formação.

Também a meu ver, no seu artigo, Cheng (1995) busca exatamente definir a literatura de Macau a partir desse sentido mais "compreensivo", buscando caracterizar justamente esse "sistema de valores" que enformam a produção escrita de língua chinesa bem como o seu vigor, já que, segundo as suas contas, no simples período citado de uma década e meia, teriam sido lançadas, em Macau, pelo menos 23 coletâneas de poesia (de língua chinesa). Esse é um dos artigos, de maior fôlego, sobre a literatura chinesa de Macau e, devido à sua restrita circulação, é pertinente acompanhar as principais informações a respeito dessa literatura, pouco conhecida entre os que não têm domínio da língua chinesa e que serão, certamente, de interesse a algumas mediações com as literaturas de língua portuguesa e de língua inglesa da região.

\section{Literatura de língua chinesa de Macau}

O professor faz, no seu texto, um pequeno histórico de como a literatura chinesa desenvolveu-se em Macau, mostrando a importância de algumas instituições e associações que apareceram no período, como a criação da Universidade da Ásia Oriental, primeira universidade moderna, na história de Macau e também a organização da "Associação da Literatura Chinesa" 
ligada à mesma universidade (CHENG, 1995). Além disso, o "Diário de Macau" (Macao Daily Newes) teria criado uma página literária, nos anos de 1980, reforçando o interesse por obras de ficção e poesia. O mesmo jornal, de acordo com o autor, promoveu um simpósio, em 1984, com a presença de escritores de Hong Kong e de Macau. Um ano depois, a Associação da Literatura Chinesa da Universidade da Ásia teria organizado e publicado a primeira coleção de obras literárias, em cinco volumes. Até então não se encontrava, em Macau, nenhuma instituição destinada a editar livros literários chineses. Em 1986, foram promovidos encontros mensais sobre a nova poesia e o "Prêmio Júnior da Literatura", patrocinado pela referida Associação, juntamente com o jornal Va Kio, o Centro Pastoral da Juventude Católica de Macau e a Federação dos Estudantes de Macau. Em 1987, foi criada a Associação dos Escritores de Macau (Pen of Macau). Em maio de 1989, fundou-se a Associação Poemas de Maio de Macau, reunindo cerca de 30 membros da mais antiga e média geração. Em 1990, foi criada a Associação de Arte Poética de Macau, destinada exclusivamente à composição dos poemas antigos. A referida Associação tem um periódico regular, desde então, a "Poesia Macaense". Já na década seguinte, 1992, foi fundada a Associação Técnica de Composição Literária de Macau, formada por um grupo acadêmico e erudito macaense que se ocupava do ensino e estudo da composição literária. No período de transição, a literatura chinesa teria passado, portanto, por uma transformação absoluta, da insuficiência de páginas destinadas à publicação de colunas literárias em jornais locais ao crescimento constante de publicações com o reconhecimento de várias regiões vizinhas, como Hong Kong e Guangzhou.

Em relação às formas estéticas da poesia contemporânea de Macau, Cheng (1995) mostra que a forma tradicional dos "ci" 
(um padrão de versos antigos) ocupa um lugar de destaque entre a comunidade, aparecendo simultaneamente em formas antigas e renovadas. Haverá, entre os poetas de versos modernos, duas facetas, uma de uma poesia suave, terna, romântica, que descreve sentimentos afetuosos ligados à natureza, e, outra, de uma poesia com inspiração mais realista, política e histórica, entre as quais se destaca a poetisa Yi Ling. Existe também uma escola que se caracteriza pela poesia "nebulosa" do interior da China, mais sugestiva e simbólica e, numa outra mão, a tendência poética modernista de expressão chinesa de Hong Kong e do ultramar mais voltada para o cotidiano e os movimentos de vanguarda. Além disso, os temas foram amplificados na literatura atual, bem como o rompimento de tabus, com o predomínio de "uma reavaliação de fundo sobre a racionalidade e valor de todas as coisas do tempo e espaço onde nos inserimos" (Cheng, 1995, p. 518).

Se tomarmos a Antologia de Poetas de Macau, organizada por Arrimar e Yao (1999, p. 226), citada anteriormente, e que reuniu 20 poetas de cada língua, podem-se observar algumas das diferentes formas poéticas referidas por Cheng na teia que vai desde imagens sutis de aspectos da natureza, mas já com algum estranhamento, como em "Cidadezinha", de Wang Hao Han, até a denúncia explícita dos problemas da cidade, como em "Paisagem de Macau", de Gao Ge, ou "Incinerador", de Wu Gao Chang:

\section{Gidadezinha}

Os raios solares decorando a cidadezinha no Outono

Mesmo as ruelas partilham da sombra do sol

A trepadeira verde sobe janelas desbotadas

e as aldrabas da porta ferrugenta fecham o silêncio. 
$[\ldots]$

Em todos as ruas apenas olhos estranhos

Eu deixo repousar a saudade nas acácias

e aguardo secretamente que Maio floresça rubro

[...] (p. 194)

\section{Paisagem de Macau}

$[\ldots]$

O Deus que protege a Praça do Cavalo de Cobre saiu do memorial ainda numa postura de dom Quixote

e os alcoviteiros adaptaram histórias eróticas com as lendas do herói.

São histórias que se repetem todas as noites

porque nas gaiolas de luxo vive-se um ambiente sensual em que os homens sobrevivem com uma sensação amorosa

Mas a questão é como manter a eterna erecção

e como fortalecer o regime representativo com o bálsamo mágico da Índia

"O jogo moderado dá prazer" é justificativa do público para se divertir

Os "Come-moedas" funcionam para criar efeitos publicitários Desde os assaltos dos piratas até aos desafios contra o rei do casino

tudo é uma combinação da civilização ocidental e da sabedoria oriental.

[...] (p. 143-144) 


\section{Incinerador}

Quando chegamos frente ao sol

o fumo preto da fábrica volta a rir cinicamente

$[\ldots]$

Trabalhar um dia todo para trocar por uma noite que se consome

no êxtase das chamas de néon

E depois refrescamo-nos com uma coca-cola gelada

As correntes de lata de estanho incorporam-se delicadamente na maré consumista

$[\ldots]($ p. 226)

Que a poesia chinesa se ponha de forma antagônica aos processos de um materialismo exacerbado que tomou conta de Macau não deve causar espanto, pois é próprio da poesia resistir aos ritos do mercado, ou tentar sobreviver apesar deles, mas evocar um certo despertencimento depois da transferência do território é quase uma subversão. Seguindo os passos da leitura de Yao (2010), no seu artigo "Em busca do habitável a partir da Antologia de Poesia Contemporânea de Macau", de Li Guanding $\left(2007^{3}\right)$, na poesia de Yi Ling, cidadã residente em Macau e portadora do bilhete de identidade de Hong Kong, há um questionamento acerca da própria possibilidade de Macau ser um lugar ao qual pode se pertencer. Segundo Yao,

3 Guanding. Li. Antologia de Poesia Contemporânea de Macau. Macau: Fundação de Macau, 2007. Citado em Yao (2010). Em busca do habitável a partir da Antologia de Poesia Contemporânea de Macau ... em Laborinho ... e Pachoco, Macau na escrita, escritas de Macau ... 
Trata-se de uma das vozes mais corajosas, moldando o seu discurso poético com uma profunda consciência de intervenção social. Como cidadã residente em Macau e portadora de bilhete de identidade de Hong Kong, Yi Ling já expressou no livro Ilha Móvel, editado em 1990, a dificuldade de identificar-se com uma terra dentro da própria terra. Nesta perplexidade, a relação entre o Eu e o país é mediada mais por aqueles valores universais do que pela cegueira do patriotismo. Como chinesa, não lhe custa identificar-se com a cultura chinesa mas ela não consegue identificar-se com um regime ainda menos democrático, o que lhe atribui uma postura dissidente que subsiste sob muita pressão numa sociedade conservadora como Macau. (2010, p. 55)

Percebes o que é o destino de repouso?

É onde a vida começa e acaba

É onde se nutrem o pensamento e o sentimento

É onde se guardam o desejo e a gratidão

É um lugar inexistente no mapa frio

mas sim é guardado quente no fundo do teu coração

(Li Guanding, 2007, p. 524. Citado em YaO, 2010, p. 55-56)

A expressão desse incômodo, no entanto, é muito incomum. Yao considera que, ao contrário, muito comum, é encontrar, na poesia chinesa, antes ainda da transferência ou logo nos anos seguintes à transferência, a imagem de Macau como "um filho humilhado" por ter sido ocupada pelos portugueses. Os chineses aguardaram com confiança o futuro da região, no entanto a série de escândalos que surgiu com relação ao governo da RAEM 
deixou a população bastante decepcionada. Apesar disso, o constante é não intervir, como aparece no poema de Lu Aolei, traduzido por Yao da seguinte forma:

O que pensa da situação actual, por favor?

Não tenho nada a dizer.

Qual é sua opinião sobre a prevenção da epidemia, por favor? Óptimo! Não aponte a câmara para mim.

Onde é que vamos, por favor?

Silêncio! Distribua as cartas!

Como é Macau de agora?

Chegue ao balcão 2 para apostar.

[...] (Li Guanding, 2007, p. 245. Citado em YaO, 2010, p. 56)

Seja nas imagens de um exílio na terra própria, na dificuldade de se enraizar, na monotonia repetida, ou seja, naquelas de vazio, de tédio e de solidão, que se sucedem nos trechos selecionados por Yao (2010) para comentar a Antologia da Poesia Contemporânea de Macau, o que vem à tona é um desconcerto muito grande, jogando o leitor contra os slogans que circulam nos discursos oficiais/ turísticos da cidade.

\section{Novas apostas: a poesia de língua inglesa}

O próprio título da apresentação de Yao (2010), no Congresso "Macau na escrita, escritas de Macau" - "Em busca do habitável" - parece reforçar a ideia de uma necessidade de os poetas de Macau pensarem o espaço vivido no cotidiano da própria cidade. Nesse sentido, talvez, o espaço linguístico da "língua comum" das vivências urbanas - o de língua inglesa, tenha crescido bastante em seus testemunhos. 
Devido às dificuldades que os chineses têm para aprender o português e vice-versa, que os portugueses têm para aprender o chinês, é comum, entre as diversas comunidades presentes hoje em Macau, que a comunicação se dê em inglês, como segunda língua, uma língua estrangeira que as diferentes comunidades vão tentando aprender. Hoje, na região, devido às oportunidades de emprego na área de serviços exigirem o domínio da língua inglesa, especialmente os cassinos e restaurantes, o ensino dessa língua vem sendo bastante reforçado. Também as migrações de mão de obra especializada do sudeste asiático e da Austrália para Macau estão formando uma nova comunidade de língua inglesa com estadia mais duradoura na região.

Num gesto bastante "novo", em 2008, Kelen e Vong publicaram uma antologia de poesia contemporânea de Macau, a primeira tentativa de reunir a poesia de Macau para um público leitor de língua inglesa, como afirma o editor na introdução do livro. Mais da metade dos poemas da antologia foram traduzidos do chinês, perto de um quarto do português e o resto foi escrito originalmente em inglês. Entre os mais de 100 poetas que participam da antologia, 33 escreveram originalmente em inglês. Isso permitiu a Kit Kellen afirmar que: "o número de poemas não traduzidos atesta a criação local de uma nova literatura inglesa" (2008, p. 18). ${ }^{4}$ Literatura inglesa ou literatura inglesa de Macau querendo dizer literatura de Macau em língua inglesa? Observo também que a maioria dos poemas chineses e portugueses dessa antologia em língua inglesa foram recolhidos das antologias anteriormente referidas (tanto as chinesas quanto a de Yao) e que o critério de seleção foi, simplesmente, poesia "de e sobre

4 Tradução livre de "[the number of untranslated poems] attests the local creation of a new English literature". 
Macau", no entanto acabou pondo em circulação numa obra conjunta onde os autores de línguas diferentes poderiam, a partir daí, conhecer a escrita uns dos outros. O trabalho foi "em processo" e durou três anos e incluiu em torno de 15 tradutores. A edição foi limitada e a sua circulação ainda é bastante restrita.

Muito elucidativa também são as palavras de Kellen (2008) ao explicar o objetivo principal da antologia: "nosso propósito, neste caso, foi criar uma antologia inclusiva com um tom democrático; isto é, representar tantas e tão variadas vozes poéticas quanto possível" (p. 18). ${ }^{5}$ Se, por um lado, o critério de seleção dessa antologia é altamente contestável, pois tanto para Yao quanto para Cheng, este "sobre Macau" pode "não significar nada" em termos de conceituação para a definição de "literatura de Macau", por não ter nenhum vínculo associativo, por outro, sem dúvida, é a mais abrangente e completa antologia de poesia contemporânea de Macau feita nos últimos tempos. Também, em relação ao termo "macaense", opta por uma postura prudente em que prefere substituir estrategicamente o termo por "de Macau". Além disso, a sua antologia dá visibilidade às comunidades minoritárias de língua inglesa ao mesmo tempo que, como língua franca utilizada em Macau, vai ao encontro de um público mais abrangente.

Kelen, australiano, professor, na Universidade de Macau, de redação criativa, poeta e editor, parece ver o espaço citadino de Macau como esse lugar de muitas possibilidades e também de determinações. Para sobreviver à intensa pluralidade de signos

5 Tradução livre de "our aim in this case has been to create an inclusive anthology with a democratic tone; that is, to represent as many and as varied poetic voices as pratical" (p. 18). 
da cidade é necessário fazer escolhas o tempo todo. Por sobre o lance dos dados mallarmeniano, no seu "Poem for Macao", faz rolar os "dados dos cassinos":

\section{Poem for Macao}

I roll the dice

and the numbers

fall out

they spread on the table

I think I hear

a sigh of relief

now luck is everywhere

for good or for ill

everyone has it

the dice are blank

as if to say

'now it's your turn -

Choose!' (Kelen, 2008, p. 123)

Próprio dos espaços urbanos hipersemiotizados, o prazer estético de redescobrir e regenerar cada vez (que os dados são lançados) a força inventiva que eles podem transmitir, existe na atenção do olhar dessa poesia, mas seria só nela? Buscar um fio de sentido às peculiaridades dessa cultura multicultural

6 Versão livre: "Poema para Macau"/ eu jogo os dados/ e os números/caem/ espalham-se na mesa/ Eu penso que escuto/ um sinal de alívio/ agora a sorte está em todo lugar/ para o bem e para o mal/ todos a têm/ os dados estão brancos/ como se dissessem/ 'agora é a sua vez - escolha'. 
parece ser um desafio aos poetas de Macau de todas as línguas. Além disso, cada vez mais, como editor, o seu trabalho vem expandindo fronteiras e, como poeta, fazendo interfaces com outras artes.

Na fascinação pela representação do espaço, em seus cursos e publicação de poesia, Kellen (2009), em seu mais novo estudo sobre a poesia da RAE de Macau, City of Poets, exploring Macao Poetry today, pergunta se ela será uma mera construção fantasista tal como entendida pela crítica em relação ao exótico, de acordo com o orientalismo concebido por Edward Saïd. Na verdade, aproveita para reconhecer a tensão que Saïd identifica na visão orientalista, entre a tendência universalizante e a de um engajamento com o "aqui" e "agora" de forma que seja produtiva para a criação poética. Aproveita a larga tradição anglo-saxã da poesia moderna, motivando os seus alunos a situarem o conhecimento particular, a isolarem elementos, tal como o define, por exemplo, a sugestão de Raymond Williams, de uma "radical particularidade", na qual, mesmo tendo sido isolados, mostrarem-se conectados a características dominantes. Como um lugar comum em meio a outras megacidades do sul da China ou do leste da Ásia, para Kellen, teoricamente, pontos anunciados por Benjamin, Bradiliard, Certeau, Zukin, Augé seriam contíguos à vontade de resistência à lógica mundial que aparece na poesia de língua inglesa mais recente. No seu estudo, tenta fazer um paralelo entre o lugar do poeta e o da cidade, na República de Platão, e o dos poetas dos tempos atuais e as novas desorientações urbanas.

Buscar a legibilidade do espaço, portanto, caracterizado dentro de uma dinâmica de desenvolvimento que mudou radicalmente o seu ambiente, as suas acessibilidades e as suas representações culturais, parece constituir um terreno comum 
às poesias de língua chinesa, de língua inglesa e, como se pode ver logo adiante, de língua portuguesa.

\section{Macau: cultura portuguesa em novos rumos}

Como já foi referido, depois da década de 1970, se dá, em Macau, uma ascensão expressiva dos valores culturais chineses, no que acarretou o incremento de publicações. Cabral e Lourenço (1993) apontam para uma total reformulação da identificação do macaense ${ }^{7}$ em relação aos tradicionais vetores que definiam o seu projeto étnico, ou seja, a associação com a língua portuguesa, a miscigenação entre sangue europeu e asiático, e a identificação com o cristianismo. Em finais da década de 1960, com a introdução da televisão em cantonês, afirmou-se progressivamente a mudança das formas de socialização da comunidade, privilegiando-se o cantonês como língua de interação. As antigas estratégias associadas ao contexto matrimonial também foram deixando de funcionar por conta da tendência que se manifestou, durante os anos 1980, de os casamentos se fazerem fora da comunidade lusófona. Os chineses assumiram, de forma crescente, os direitos de cidadania, em um movimento que convergiu com o da classe média que participava do contexto da lusofonia. De acordo com

\footnotetext{
7 Genericamente, termo usado para designar os euro-asiáticos de cultura portuguesa, numa formulação que, claramente, distingue e separa as famílias chineses que também residem no território numa longa duração, mas que, aos olhos da sociedade euro-asiática, eram inscritos simplesmente na "cultura chinesa". Nunca houve a preocupação de se fazer uma caracterização dos "chineses de Macau" ou "chineses macaenses". O primeiro e único trabalho científico que se ocupou da comunidade chinesa de Macau é o de Santos e Gomes (1998) e teve a sua circulação impedida ou dificultada, em Macau, nos anos de transição.
} 
os autores, os macaenses deixaram de se apresentar como promotores do projeto privilegiado dos portugueses (colonial), ${ }^{8}$ passando a legitimar a sua presença em virtude da contribuição histórica que Macau trouxe para a própria China. A ação discursiva dos macaenses passou a recair, fundamentalmente, sobre a interculturalidade no sentido de se caracterizar uma condição cultural "especial" do território.

Destituídos da possibilidade de manifestar a sua vontade política, através de uma representação oficial no contexto das negociações que determinaram a transferência da soberania, ficaram, portanto, com a pertença cultural dessa condição que se formulou como "condição especial". As transformações do projeto étnico macaense, mencionadas por Cabral e Lourenço (1993), surgiram nesse fluxo de articulação das determinações políticas com a elaboração dos significados da sua formação e presença na região. Juntamente com a transformação do projeto étnico macaense que é analisada por Cabral e Lourenço, ocorreu uma alteração dos modos de recepção da produção literária dos escritores macaenses enquadrados na lusofonia.

8 É possível considerar que, apesar de Macau não ter sido propriamente uma "colônia", até porque o seu estatuto político só foi clarificado, no período de transição, depois que Macau foi inserido no contexto dos "tratados desiguais" e, ainda, principalmente, depois que a tese histórica de Fok Kai Cheong, acerca das bases da instalação dos portugueses na região, começou a circular, existiu, em Macau, uma administração colonial, uma educação em acordo com as sociedades coloniais e formas de socialização afins às coloniais e, portanto, a região foi eivada de discursos no âmbito dos colonialismos, de forma muito marcada, no período de 1880 até os anos de 1970 em que o capital cultural chinês começou a preponderar. O que quero afirmar é que associar Macau à crítica pós-colonial é perfeitamente plausível. Como afirmou Ana Mafalda Leite, no seu Literaturas Africanas e Formulações Pós-Coloniais (2003), a crítica pós-colonial não pode ser atrelada de forma restrita nem aos países recém independentes nem a um sentido cronológico. $\mathrm{O}$ termo diz respeito à crítica que analisa, frustra e desconstrói as estratégias discursivas formadas no âmbito dos impérios. 
A recepção de textos dos mais conhecidos representantes da comunidade macaense, de matriz portuguesa, José dos Santos Ferreira, Luís Gonzaga Gomes, Deolinda da Conceição e Henrique de Senna Fernandes passou a ser atualizada em função de uma acumulação de significados que correspondem à tradição do passado de uma (grifo meu) dentre as várias etnias que compõem o território, deslocando uma perspectiva que abrangia esses textos como a representação de uma força cultural dominante (colonial) para uma de diversidade cultural.

A memória coletiva dos macaenses legitima, sem dúvida, uma identidade cultural bastante particularizada de Macau, evocando uma cultura crioula que pode ser identificada na língua própria de Macau (patoá de Macau), e que, hoje, apesar de ter perdido a sua função comunicativa, foi reavivada, recentemente, com a criação do grupo Papiaçam di Macau, dirigido por Miguel de Senna Fernandes. Com certeza, é na culinária que o padrão dessa cultura mestiça é mais vivo e forte.

No período de transição, de 12 anos, a alteração do modo de se compreender a presença cultural portuguesa foi seguindo as transformações das infra-estruturas pelas quais a região passou e que serão descritas no próximo capítulo. O que interessa a este trabalho é que esse mar de empreendimentos e acontecimentos que transcorreram em Macau foi responsável pelo retorno ao território de macaenses que viviam diasporicamente e antigos residentes portugueses que haviam partido em decorrência da situação do Pós-Guerra, acionando antigas solidariedades do eixo familiar e/ou do círculo de amizades. Foi também responsável pela transferência de vários portugueses, tanto de Lisboa quanto dos países africanos, para Macau - seja por se enquadrarem nos quadros funcionais das instituições públicas, seja por buscarem melhores oportunidades de trabalho na iniciativa privada. 
Das rotas africanas surgiram, na poesia, modulações de vozes e ritmos que procuram marcar a fusão de tempos ou de fragmentos espaciais, como os que aparecem nas poesias de Jorge Arrimar e de João Rui Azeredo, ou ainda, de Alberto Estima de Oliveira. Nota-se, nesses escritores, no período de transição, a presença de uma preocupação comum em ancorar sentidos do tempo histórico em seus textos, por conta das transformações culturais radicais pelas quais passou a região. Portugueses que cruzaram a RAE de Macau, como José Augusto Seabra, em seu Poemas em nome de Deus (1990), ou José Jorge Letria, em seu Oriente da mágoa (1992), acabam por ativar, inclusive, os sentidos míticos da possível presença de Camões na região e também da história de Portugal. Este último livro, um longo poema narrativo, retoma, por exemplo, o exílio de Camões, dentro de uma noção decadentista que se formou, na Europa, com relação ao oriente, nos séculos XVIII e XIX, fixando-o dentro da visão romântica. De uma forma bem mais complexa, estará Macau representada, em meio a outras localidades, no oriente de Até ao longínquo China navegou ..., de Antônio Manuel do Couto Viana, publicado pelo Instituto Cultura de Macau, em 1991. Todas essas obras precisariam ser estudadas, de forma cuidadosa e atenta, para que se pudesse fazer uma análise mais rigorosa da significação de Macau.

Na RAE de Macau, enquanto a fugacidade e o provisório eram conceitos sinalizadores da ruptura eminente, que emergiam em textos diversos, uma demanda de rememorações procurava resistir à voracidade do tempo. Na poesia, é possível verificar que os poetas produziram um inventário de referências do espaço urbano, tornando-se cúmplices da(s) cultura(s) outra(s), mas, de algum modo, não deixam de situar Macau como um signo que interroga as suas próprias qualidades. 
Em Margens do Destino. Macau e a literatura em língua portuguesa (SIMAS, 2007a), foi feita a análise de várias obras entre elas Chü Kong, de Maria do Rosário Almeida (1987), também da obra de João Rui de Azeredo (1992), de Fernanda Dias (2002) e, ainda, da prosa do mesmo período, para o qual se remete o leitor. Desta última autora seria interessante que se desse a conhecer este primeiro poema do livro Chá verde:

\section{definição}

chá: esse outro meu coração verde

que fora do meu peito pulsa.

ritual de silêncio, amargo e quente,

que te dou a beber em cada taça

(DIAS, 2002, p. 13)

O poema abriga, de cara, uma alta interação com esse "outro" cultural, o que vai se revelar também no fato de traduzir e recontar poesia e estórias das comunidades chinesas de Macau. Fez versões para a poesia de Wong Io Fong, conhecido por Gao Ge e para a poesia de Shu Wang, além de, em 2011, num gesto admirável, ter publicado uma versão poética do Yi Jing, ${ }^{9}$ o clássico livro das mutações, que está tanto na base do pensamento taoísta quanto na do confucionismo, sendo considerada, portanto, uma das obras mais importantes do enraizamento cultural.

Própria das transculturalidades é a convivência da habitação de mais de um código cultural na ação ético-social, nos modos de se falar, ou seja, nos usos da linguagem.

9 Escrevi um ensaio sobre essa obra de Fernanda Dias, a ser publicado na Revista de Cultura do ICM. 


\section{Conclusão}

Do ponto de vista da multiculturalidade, a literatura de Macau apresenta-se bastante rica, com um vasto repertório e com instigantes perspectivas para a crítica. Ao se questionar sobre a possibilidade de essa literatura ser percebida em sua forma plural, acredita-se que ela pode, ainda, revelar uma contribuição ímpar às próprias definições do fenômeno literário, constituindo uma elaboração em processo daqueles limites axiais produzido mais em função da alteridade do que de definições de identidades.

\section{Referências}

Abbas, Ackbar. Hong Kong: Gultural and the Politics of Disappearance. 3. ed. Minnesota: University of Minnesota Press, 2002.

AlmeidA, Maria do Rosário. Chü Kong. Macau: Instituto Cultural de Macau, 1987.

ARrimar, Jorge. Secretos sinais. Macau: Instituto Cultural de Macau, 1992.

Arrimar, Jorge; YaO, Jingming (Sel. e Org.). Antologia de Poetas de Macau. Macau: Instituto Camões, Instituto Cultural de Macau, Instituto Português do Oriente, 1999.

Augé, Marc. Não lugares. Introdução a uma antropologia da supermodernidade. Campinas: Papirus, 1994.

Azeredo, João Rui. Poemacau. Macau: Livros do Oriente, 1992. Brookshaw, David. A escrita em Macau: uma literatura de circunstâncias ou as circunstâncias de uma literatura. In: 
Laborinho, Ana Paula; Pinto, Marta Pacheco (Org.). Macau na escrita, escritas de Macau. Vila Nova de Famalicão: Húmus, 2010. p. 19-30.

Cabral, João de Pina; Lourenço, Nelson. Em terra de tufões. Dinâmica da etnicidade macaense. Macau: Instituto Cultural de Macau, 1993.

Candido, Antonio. O escritor e o público. In: Candido, Antonio. Literatura e Sociedade: estudos de teoria e história literária. 7. ed. São Paulo: Nacional, 1985. p. 73-88.

Candido, Antonio. A literatura na evolução da comunidade. In: Candido, Antonio. Literatura e Sociedade: estudos de teoria e história literária. 7. ed. São Paulo: Nacional, 1985. p. 139-167. 1a edição de 1967.

Cheng, Wai-Ming. Literatura Chinesa de Macau entre os anos oitenta e os princípios da década de noventa. Revista Administração, v. 8, n. 29, p. 501-523, 1995.

Couto Viana, António Manuel. Até o longínquo China navegou. Macau: Instituto Cultural de Macau, 1991.

Dias, Fernanda. Chá Verde. Macau: Círculos de amigos da cultura de Macau, 2002.

Kelen, Christopher. City of Poets, exploring Macao Poetry today. Macau: ASM, 2009.

Kelen, Christopher; Vong, Agnes (Org.). I roll the dice. Macau: Association of Stories in Macau, 2008.

Laborinho, Ana Paula. Introdução. In: Laborinho, Ana Paula; PINTO, Marta Pacheco (Org.). Macau na escrita, escritas de Macau. 
Vila Nova de Famalicão: Húmus, 2010. p. 9-16.

Laborinho, Ana Paula. Apresentação. In: Arrimar, Jorge; YaO, Jingming (Sel. e Org.). Antologia de Poetas de Macau. Macau: Instituto Camões, Instituto Cultural de Macau, Instituto Português do Oriente, 1999.

LeIte, Ana Mafalda. Literaturas Africanas e Formulações Pós-Coloniais. Lisboa: Colibri, 2003.

Letria, José Jorge. Oriente da mágoa. Macau: Instituto Português do Oriente, 1992.

Moraes, Anita. Espaço e representação em Ruy Duarte de Carvalho. In: Alves, Ida; Lemos, Masé; Negreiros, Carmem (Org.). Estudos de paisagem: literatura, viagem e turismo cultural. Rio de Janeiro: Oficina Raquel, 2014.

Olinto, Heidrun Krieger. Histórias da Literatura: as novas teorias alemãs. São Paulo: Ática, 1996.

Rocha, Rui. Macau, Sociedade Multicultural? Revista da Cultura, Macau, II Série, n. 78, p. 26-35, out. 1998.

Santos, Boaventura de Sousa; Gomes, Conceição. Macau: o pequeníssimo dragão. Lisboa: Edições Afrontamento, 1998.

Seabra, José Augusto. Poemas em nome de Deus. Macau: Instituto Cultural de Macau, 1990.

Simas, Monica. Margens do Destino: Macau na literatura em língua portuguesa. São Caetano: Yendis, 2007a.

Simas, Monica. De Portugal à África a Macau: exclusões, inclusões. Via Atlântica, São Paulo, n. 12, p. 67-77, 2007 b. 
Von Sydow, Evandro Luis. F(r)icções Goesas: vários mundos numa só vida. Tese (Doutorado em Letras) - Universidade Federal Fluminense, Niterói, RJ, 2008.

Wordie, Jason. Macao. People and places, past and presente. Hong Kong: Angsana, 2013.

YAO, Jingming. Em busca do habitável a partir da Antologia de Poesia Contemporânea de Macau. In: Laborinho, Ana Paula; PInTo, Marta Pacheco (Org.). Macau na escrita, escritas de Macau. Vila Nova de Famalicão: Húmus, 2010. p. 49-61.

Simas, Monica. Macau: uma literatura plural? In: Simas, Monica (Org.). Estudos sobre Macau e outros orientes. São Paulo: Paulistana, 2017. p. 68-94. 